\title{
La Coupe
}

\section{Martine Audet}

When "blood wants to be light," in Martine Audet's hand, it becomes a poem.

Des coupures, des lignes, des points puis le sang nettoie un peu la sueur, libère le ciel (grumeaux de roses contre nos bouches). Est-ce la clairvoyance des aimées? les étoiles trop grandes qui se tiennent en nous comme des mots? Le sang veut être la lumière. La lumière et sa soif.

À partir de la page 279 du journal de Hervé Guibert, je lis à rebours. Je m'éloigne du dénouement (ce soulèvement extrême du coeur) cherchant un passage où le cœur (le corps?) est comparé à une coupe de sang qui toujours menace de déborder. Je reconnais peu de choses: maints fragments semblent appartenir au très flou d'un rêve jamais mis en mots. 


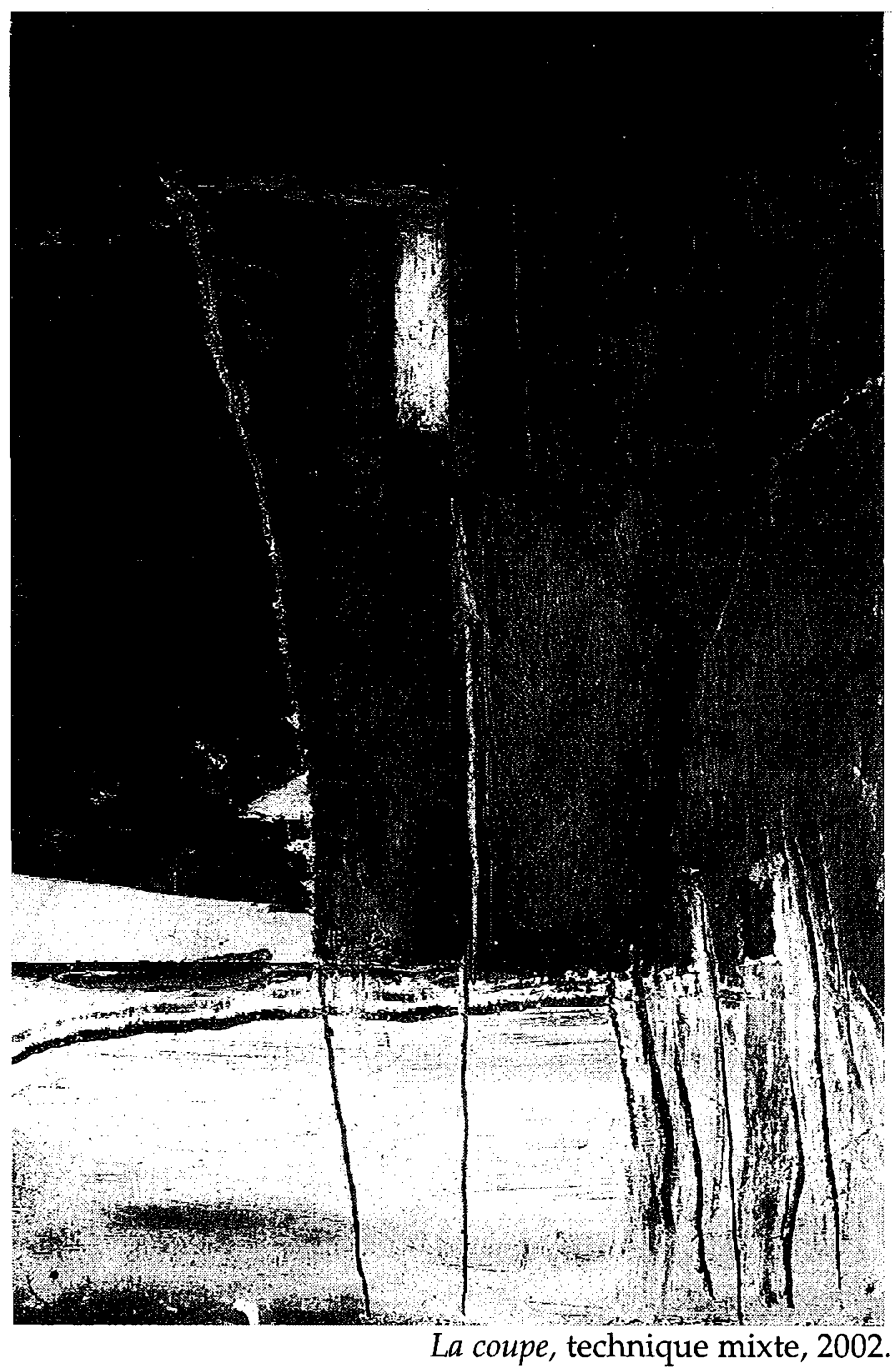




\section{La Coupe}

1 -

le ciel dans tous les corps. et des cerises. la bouche est grande. comme de l'amour. les jours plus libres. je note: l'air fauve et nos manteaux de sang.

2-

en souvenir d'une main. le sang est notre table. et ce qui va. sans rien tenir. est-ce une leçon? je note: un bruit de chaises et tes figures aimées.

3-

l'envie de toucher à. l'alcool du coeur. aujourd'hui. comme au devant des pierres. le corps du corps qui a froid. je note: des bêtes de toutes sortes s'enferment dans l'attente.

$4-$

une toile de sang. sous les paupières. et ce qui tremble.

de la couleur. je ne meurs pas. je note: ton nom perdu

dans la lumière. 